\title{
Acceptability and tolerability of alcohol- based hand hygiene products for elderly residents in long-term care: a crossover study
}

Margaret O'Donoghue ${ }^{1 *}$, Jacqueline M. C. Ho ${ }^{1}$, Didier Pittet $^{2}$ and Lorna K. P. Suen ${ }^{1}$

\begin{abstract}
Background: Hand hygiene is a critical component of infection control. Much of the focus on improving hand hygiene in healthcare settings has been directed towards healthcare worker compliance but its importance for patients, including those in long-term care facilities (LTCFs), is increasingly being recognised. Alcohol-based hand rub (ABHR) can lead to improved compliance. We aimed to determine acceptability and tolerability of two ABHRs for hand hygiene of elderly LTCF residents using a modified version of the WHO protocol.

Methods: Thirty six elderly LTCF residents participated in this crossover study. A modified and translated (Chinese) version of the WHO protocol for evaluation of two or more ABHRs was used to determine product acceptability and tolerability for one gel (bottle with reclosable cap) and one foam (pump). During the 3-day testing period, participants were provided with their own portable bottle of ABHR. A research nurse objectively assessed the skin integrity of the hands at baseline and throughout the study. Skin moisture content was determined using a Scalar Moisture Checker Probe (Science Technology Resources, Ca, USA). Participants rated ABHR tolerability and acceptability using the WHO checklist at the end of each test period.

Results: Both products passed the WHO criteria for acceptability and tolerability. The foam (86\%) scored higher than the gel (51\%) for ease of use possibly because some participants found the cap of the gel bottle difficult to open due to finger stiffness. No evidence of damage to skin integrity was observed. Overall, skin moisture content had improved by the end of the study. Residents preferred either of the test products to the liquid formulation currently in use by the LTCF.

Conclusions: Overall, the elderly were willing to use ABHR for hand hygiene. Both products were well tolerated and preferred over the usual product provided by the LTCF. However, forgetfulness and difficulty rubbing the product over the hands due to finger stiffness posed a challenge for some residents. This could be overcome by using healthcare worker-assisted hand hygiene at specified times each day and prompts to serve as reminders to perform hand hygiene.
\end{abstract}

Keywords: Hand hygiene, Alcohol-based hand rub, Long-term care facility; Elderly hand hygiene; Tolerability, Acceptability, World Health Organization

\footnotetext{
* Correspondence: Margaret.o.donoghue@polyu.edu.hk

${ }^{1}$ Squina International Centre for Infection Control, School of Nursing, The

Hong Kong Polytechnic University. Hung Hom, Kowloon, Hong Kong

Full list of author information is available at the end of the article
}

(c) The Author(s). 2019 Open Access This article is distributed under the terms of the Creative Commons Attribution 4.0 International License (http://creativecommons.org/licenses/by/4.0/), which permits unrestricted use, distribution, and reproduction in any medium, provided you give appropriate credit to the original author(s) and the source, provide a link to the Creative Commons license, and indicate if changes were made. The Creative Commons Public Domain Dedication waiver (http://creativecommons.org/publicdomain/zero/1.0/) applies to the data made available in this article, unless otherwise stated. 


\section{Background}

Elderly residents in long-term care facilities (LTCFs) are at increased risk of colonization or infection with multidrug resistant organisms (MDROs) [1, 2]. Infections caused by MDROs result in increased morbidity and mortality, frequent hospitalization and an increased demand for treatment using newer, more expensive antibiotics [2]. Residents of LTCFs are recognized as an important reservoir of MDRO in hospital settings [3, 4]. Hospitalization, in turn, may lead to colonization of previously uncolonized residents who then carry the MDRO to the home upon discharge [3]. Colonized or infected residents may have MDRO contamination of their hands [5]. Such hand contamination could lead to cross-transmission by direct contact with staff of the home or other residents [5], or indirectly via environmental contamination $[2,6]$. In a study involving elderly patients at a post-acute care facility, $11 \%$ had methicillin-resistant Staphylococcus aureus (MRSA), and $13.7 \%$ vancomycin resistant enterococcal contamination of their hands [7]. In a separate study of MRSA nasal carriage, 95\% (40/42) of elderly LTCF residents with proven nasal carriage, were also culture positive for hand contamination with MRSA [8]. Organisms such as MRSA and vancomycin resistant enterococci (VRE) can be transmitted indirectly via the environment [9]. A study conducted in a veterans affairs nursing home in the US noted that direct contact between residents and staff occurred frequently in the common areas of the facility outside of the resident's room (5.8 times per hour), while contact between residents and the environment occurred 12.2 times per hour and this occurred most often in the dining room [10]. This study did not include contact between staff and patients during patient care procedures.

In the past, the focus was mainly on attempts to improve healthcare worker hand hygiene compliance with sometimes limited success [11]. More recently, the role of the patient's hands in transmission of infection is receiving increased attention [12,13] and efforts have been made to improve patient hand hygiene, particularly in the acute care setting [14].

Improving hand hygiene in elderly residents in LTCF could be an important infection control measure that would relieve the burden of healthcare associated infections. Although hand-washing facilities are provided in all LTCFs, these may not be readily accessible for many elderly residents if they have limited mobility. Alcoholbased hand rub (ABHR) is usually provided but few studies have investigated acceptability of ABHR for hand hygiene amongst this group. We aimed to investigate the acceptability and tolerability of two ABHRs for elderly residents in long-term care using a modified version of the World Health Organisation (WHO) Protocol Method 2 [15] for evaluation of two or more hand hygiene products.

\section{Methods}

\section{Setting}

This was a crossover study involving a convenience sample of elderly participants from a LTCF for the elderly in Hong Kong. The study was performed between February and March 2016.

Existing practices in the LTCF did not focus on elderly hand hygiene. Dispensers of ABHR $(500 \mathrm{~mL}$ volumes of liquid rinse) were wall-mounted at a few sites in the home but most hand rub was placed at the nurses' station and the emphasis was placed on staff hand hygiene.

\section{Study design}

The study was based on a modified version of the WHO published protocol 'Method for evaluation and comparison of tolerability and acceptability of different alcoholbased hand rubs: Method 2' [15]. This method is used for the evaluation of two or more ABHRs. Since this protocol was originally designed for healthcare workers, we removed some questions that would not apply to our target group of elderly residents. Subjects were not asked to stop using hand care products during the study period. Questions on whether the subject suffered from irritative or atopic dermatitis, rhinitis/allergic conjunctivitis, asthma, or intolerance to alcohol were omitted from the checklist and instead the information for each participant was obtained from the staff of the home. Any subject suffering from any of these conditions was excluded from the study. We inserted a question on product preference at the end of the checklist. The modified checklist as well as rationale for modification/deletion of some questions are available as Additional file 1: Table S1 (a) and Additional file 2: Table S1 (b) respectively.

The modified checklist was translated to Chinese and back translated to English by a separate translator to confirm accuracy of the translation. The finalized checklist was administered to ten elderly residents of a separate LTCF to check their understanding of the questions and ability to answer.

The nurse in charge at the LTCF assisted in identifying 36 residents that were willing to participate in the study, and were capable of providing informed consent, and answering the questions from the WHO checklist.

Prior to distributing the first ABHR, all participants attended a workshop demonstrating correct use and benefits of ABHR for hand hygiene. A nurse then assessed the skin condition of all subjects [15]. Participants were asked to use each of two ABHRs (Product A and B) exclusively for hand hygiene over a three-day period. A portable bottle of Product A was then distributed to all participants. A two-day washout period was imposed before switching to Product B. Subjects were requested to avoid the use of other ABHR for the duration of the study. A flow chart outlining the protocol used is provided in Fig. 1. 
1. Obtain Informed consent

$\downarrow$

2. Check skin integrity of both hands

$\downarrow$

3. Check moisture content of hands

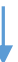

4. Complete WHO Checklist Part I

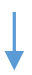

5. Workshop and demonstration/return demonstration on use ABHR

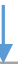

6. Distribute Product A to each participant

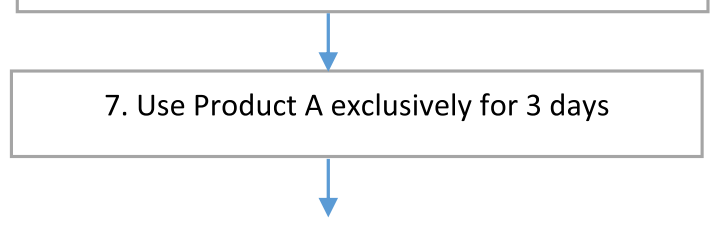

8. Stop use of Product A. Collect back bottles.

Measure volume of ABHR consumed

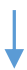

9. Complete Checklist Part II for Product A

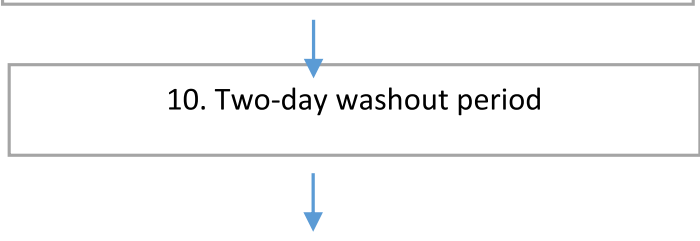

11. Distribute Product B to each participant

Repeat steps 2-3; 7-9 for product B

Fig. 1 Flow chart of the protocol conducted to determine acceptability and tolerability of two ABHR hand hygiene products

\section{Products $A$ and $B$}

Product A was a gel (Microshield Angel blue antimicrobial hand gel; www.schuelke.com) which contains 70\% ethanol plus a moisturizer and emollient. It has a light fragrance and is blue in colour. A pocket-sized bottle (125 ml volume) with a reclosable cap was distributed to participants. Product B was a fragrance-free foam with emollient (Avagard ${ }^{\mathrm{Tm}} ; 3 \mathrm{M}^{\mathrm{Tm}}$ ). The active ingredient is $70 \%$ $\mathrm{v} / \mathrm{v}$ ethanol. The portable version is provided in $50 \mathrm{~mL}$ volumes in a pushdown, lightweight pump bottle.

The accompanying instructions for both products required application of sufficient product to thoroughly wet all surfaces of the hands and fingers and then rub for at least $30 \mathrm{~s}$ or until dry. To determine the volume of ABHR used during the test periods, the bottles were weighed before distributing and again at the end of the test period.

\section{WHO checklist}

The checklist [15] consisted of two parts (Questionnaire Parts I and II). Part I gathered information on demographics as well as current practices with respect to hand hygiene and skin care. This was completed once only for each participant prior to commencing the testing phase. Part II investigated acceptability and tolerability of each $\mathrm{ABHR}$ and was completed at the end of Day 3 for each product tested. All checklists were completed in a communal room provided by the LTCF. Where necessary, assistance in answering the questions was provided for subjects by research study staff.

\section{Determination of skin integrity and moisture content}

The research nurse evaluated the skin health of the hands of participants for redness, scaliness, fissures or any other evidence of a skin reaction to the test products. The moisture content was determined using a Scalar moisture checker probe (Scalar moisture checker for skin, Science Technology Resources, Ca, USA). This was applied to the skin using gentle pressure and a digital reading recorded. Moisture content checking was performed in duplicate and a mean value determined. The probe was decontaminated using an alcohol wipe before proceeding to the next participant. The same site on the back of the hand was tested for each subject to ensure consistency of sampling.

\section{Workshop on use of ABHR}

A workshop and training session were provided by the research nurse to demonstrate correct use of ABHR by elderly residents and explain the benefits of using ABHR for hand hygiene. Participants were particularly encouraged to use ABHR before each of the main mealtimes but to wash their hands if they were visibly soiled. Since many residents may find it difficult to remember all 
seven steps for hand hygiene [16], we used the simplified three-step protocol of Tschudin-Sutter et al. [17]. Participants were instructed to apply a sufficient volume of ABHR to fill the palm of one cupped hand and then Step 1: rub hands together carefully; Step 2 rub the fingertips of one hand in the palm of the other to the best of their ability, and finally Step 3 perform rotational rubbing of both thumbs. Emphasis was placed on Step 1. Participants continued to rub hands together until the hands felt dry [17].

All subjects were given the opportunity to practice using the ABHR during the workshop and repeated demonstration and return demonstration was provided. Healthy elderly volunteers from our university's Institute for Active Aging also attended the workshop as ambassadors for hand hygiene. They demonstrated hand rubbing with ABHR and encouraged participants to practice. Each subject was given a personal portable bottle of ABHR (Product A) at the end of the workshop. Leaflets with a simple diagram of instructions on use of ABHR were distributed to each elderly subject to serve as a reminder of technique.
During the test period, a schedule was created to ensure that elderly ambassadors, student nurse helpers, and/or the research nurse, visited the LTCF daily to check on participants' compliance with use of ABHR, remind them to use their ABHR, and ensure there was no skin irritation or other problems arising during the test period. Any elderly subject observed to have difficulty manipulating the ABHR bottles or performing the hand rubbing action, was assisted by nursing student helpers who used gloved hands to help rub the product into the hands.

\section{Data analysis}

All data were entered for analysis into SPSS version 23 . To comply with the WHO protocol, descriptive statistics were used for results presentation. Evaluation of tolerability and acceptability of both ABHRs was performed according to the WHO protocol [9]. In Questionnaire Part II: "Evaluation of the Test Product" the items colour and smell (fragrance) must score $>50 \%$ above four in the seven-point scale while all other items (texture, irritation, drying effect, etc.) must score $>75 \%$ above four.

Table 1 Subject demographics and responses to the WHO checklist for hand hygiene product tolerability and acceptability

\begin{tabular}{|c|c|c|c|c|c|}
\hline Demographics & Age range & Frequency (\%) & & & \\
\hline & $70-75$ & $4(11.1)$ & & & \\
\hline & $76-80$ & $4(11.1)$ & & & \\
\hline & $81-85$ & $6(16.67)$ & & & \\
\hline & $86-90$ & $12(33.33)$ & & & \\
\hline & $91-95$ & $8(22.27)$ & & & \\
\hline & $>95$ & $1(2.78)$ & & & \\
\hline & Missing & $1(2.78)$ & & & \\
\hline Mean $\pm S D$ in years & $85 \pm 8.25$ & & & & \\
\hline \multirow[t]{2}{*}{ Sex } & Female & $25(69.4)$ & & & \\
\hline & Male & $11(30.6)$ & & & \\
\hline Evaluation of factors influencing skin tolerance & & & \multicolumn{3}{|c|}{ Response Options } \\
\hline \multirow{6}{*}{$\begin{array}{l}\text { Use of a protective hand lotion/cream } \\
\text { (outside of the test period) }\end{array}$} & & & \multicolumn{2}{|c|}{ As often as possible } & $1(2.8)$ \\
\hline & & & \multicolumn{2}{|c|}{ Several times per day } & $6(16.7)$ \\
\hline & & & \multicolumn{2}{|c|}{ Once per day } & $4(11.1)$ \\
\hline & & & \multicolumn{2}{|l|}{ Sometimes } & $1(2.8)$ \\
\hline & & & \multicolumn{2}{|l|}{ Rarely } & $1(2.8)$ \\
\hline & & & \multicolumn{2}{|l|}{ Never } & $23(63.9)$ \\
\hline \multirow{4}{*}{$\begin{array}{l}\text { Do you think you can improve your own } \\
\text { hand hygiene compliance? }\end{array}$} & & & \multicolumn{2}{|l|}{ Yes } & $22(61.11)$ \\
\hline & & & \multicolumn{2}{|l|}{ No } & $5(13.89)$ \\
\hline & & & \multicolumn{2}{|l|}{ Perhaps } & $7(19.44)$ \\
\hline & & & \multicolumn{2}{|l|}{ Missing } & $2(5.56)$ \\
\hline \multirow{4}{*}{$\begin{array}{l}\text { It may be difficult for you to use an alcohol-based } \\
\text { hand hygiene product because of: }\end{array}$} & & Always & Sometimes & Never & Missing \\
\hline & Forgetfulness & $6(16.67)$ & $17(47.22)$ & $11(30.56)$ & $2(5.56)$ \\
\hline & Lack of time & $1(2.78)$ & \multirow[t]{2}{*}{0} & 33 (97.1) & $2(5.56)$ \\
\hline & Damaged skin & $1(2.78)$ & & 33 (91.67) & $2(5.56)$ \\
\hline
\end{tabular}


When presenting the results of the seven-point Likert scale used to determine product acceptability, scores were pooled as follows: $1-3$ (low rating); $4-5$ (neutral); 6-7 (highly rated) for data analysis purposes. Data on skin moisture content was interpreted following manufacturer's instructions (Additional file 2: Table S2) for interpretation of readings for the Scalar moisture checker probe.

\section{Results}

Overall, 36 residents participated in the study. Demographic details and factors influencing skin tolerance to ABHR are shown in Table 1. Although residents came together at mealtimes, their assigned rooms were spread over five floors of the LTCF; 12 residents (33\%) were located on the first floor; 14 (39\%) on the second; eight (22\%) on the fourth floor and one resident each $(2.8 \%)$ on the third and fifth floors. The mean age was 85 years (standard deviation \pm 8 ; range 70-98); 25 (70\%) were female. Almost 31\% of participants claimed to use hand lotion at least once per day (36\% of females; $18 \%$ of males). The majority of participants (61\%) thought they could improve their own hand hygiene. A large proportion $(68 \%)$ thought that forgetfulness, but not a lack of time, nor the possibility of damage to skin, could hinder their ability to use ABHR for hand hygiene (Table 1).

Both tested ABHRs passed the WHO criteria for product tolerability and acceptability (Table 2). The majority of residents thought that both ABHRs dried quickly and that neither product felt sticky. More than $90 \%$ reported no drying effect on the hands. There was a notable difference in ratings for 'ease of use' (Fig. 2) with the majority of subjects $(86 \%)$ finding the foam pump easier to manipulate than the portable bottle of gel (51\%). A similar result was observed for "application"; $86 \%$ of participants thought the foam was pleasant to apply while only $67 \%$ rated application of the gel as pleasant. All participants reported no irritation when using the foam but $14 \%$ thought the gel caused irritation. Overall, participants were very satisfied with both ABHRs (Table 2) but rated the foam more highly (83\%) than the gel (64\%).

Data on frequency of hand hygiene practices is shown in Table 3. After completion of the first test period (Product A, gel), $50 \%$ of participants thought that the study had changed their hand hygiene practices. By the end of the study, this figure increased to $69 \%$. Half of the participants $(50 \%)$ claimed to practice hand hygiene at least $1-5$ times per day during the test period. Participants $(42 \%)$ noted a major difference between Product B (foam) and the product normally used in the LTCF (Table 4 ) and at least $50 \%$ preferred the test products to their usual product (69\% for the foam). One-third of subjects $(33 \%)$ thought that the gel could improve their hand hygiene compliance while $75 \%$ thought that use of
Table 2 Evaluation of acceptability of both ABHR test products according to $\mathrm{WHO}$ criteria\# $^{\#}$

\begin{tabular}{|c|c|c|c|c|c|}
\hline \multirow[t]{2}{*}{ Variable } & \multirow[t]{2}{*}{ Rating } & \multicolumn{2}{|c|}{$\underline{\text { Product A (Gel) }}$} & \multicolumn{2}{|c|}{ Product B (Foam)^ } \\
\hline & & $\mathrm{N}$ & $\%$ & $\mathrm{~N}$ & $\%$ \\
\hline \multirow[t]{3}{*}{ Colour } & Pleasant & 14 & 38.89 & 12 & 38.33 \\
\hline & Neutral & 22 & 61 & 22 & 61.11 \\
\hline & Missing & 0 & 0 & 2 & 5.56 \\
\hline \multirow[t]{3}{*}{ Smell } & Pleasant & 19 & 52.78 & 14 & 38.89 \\
\hline & Neutral & 16 & 44.4 & 20 & 55.56 \\
\hline & Unpleasant & 1 & 2.78 & 0 & 0 \\
\hline \multirow[t]{4}{*}{ Texture } & Not sticky at all & 33 & 91.67 & 33 & 91.67 \\
\hline & Neutral & 2 & 5.55 & 1 & 2.78 \\
\hline & Sticky & 1 & 2.77 & 0 & 0 \\
\hline & Missing & 0 & 0 & 2 & 5.56 \\
\hline \multirow[t]{4}{*}{ Irritation } & Not irritating & 30 & 83.33 & 34 & 94.44 \\
\hline & Neutral & 1 & 2.77 & 0 & 0 \\
\hline & Irritating & 5 & 13.88 & 0 & 0 \\
\hline & Missing & 0 & 0 & 2 & 5.56 \\
\hline \multirow[t]{4}{*}{ Drying effect } & Not at all & 33 & 91.7 & 32 & 88.89 \\
\hline & Some & 2 & 5.6 & 1 & 2.78 \\
\hline & A lot & 1 & 2.8 & 1 & 2.78 \\
\hline & Missing & 0 & 0 & 2 & 5.56 \\
\hline \multirow[t]{4}{*}{ Ease of use } & Very easy & 18 & 51.43 & 31 & 86.11 \\
\hline & Neutral & 9 & 25 & 3 & 8.33 \\
\hline & Very difficult & 8 & 22.2 & 0 & 0 \\
\hline & Missing & 1 & 2.78 & 2 & 5.56 \\
\hline \multirow[t]{3}{*}{ Speed of drying } & Fast & 32 & 88.89 & 34 & 94.44 \\
\hline & Medium & 2 & 5.56 & 0 & 0 \\
\hline & Missing & 2 & 5.56 & 2 & 5.56 \\
\hline \multirow[t]{3}{*}{ Application } & Pleasant & 24 & 66.67 & 31 & 86.11 \\
\hline & Neutral & 12 & 33.3 & 3 & 8.33 \\
\hline & Missing & 0 & 0 & 2 & 5.56 \\
\hline \multirow[t]{3}{*}{ Overall } & Very satisfied & 23 & 63.89 & 30 & 83.33 \\
\hline & Neutral & 13 & 36.1 & 4 & 11.11 \\
\hline & Missing & 0 & 0 & 2 & 5.56 \\
\hline
\end{tabular}

\#WHO criteria for product acceptability: Items Colour \& Fragrance (smell): must achieve a rating of $\geq 50 \%$ above 4 (neutral to very satisfied). All other items: $\geq 75 \%$. Both ABHR products tested fulfilled the criteria

$\wedge$ Two subjects were hospitalized during the washout period and were unable to participate in testing of product $B$

the foam could improve compliance. Overall, 53\% preferred the foam to the gel for hand rubbing. The volume of $\mathrm{ABHR}$ used was low: assuming a minimum volume of $1.5 \mathrm{~mL}$ of ABHR should be used during each hand hygiene opportunity, $4.5 \mathrm{~mL}$ would be consumed daily if hand rubbing was performed three times per day. However, only $36 \%(13 / 36)$ of residents used $>6 \mathrm{ml}$ of product (data not shown). Despite this, there appeared to be an overall improvement in skin moisture content (Fig. 


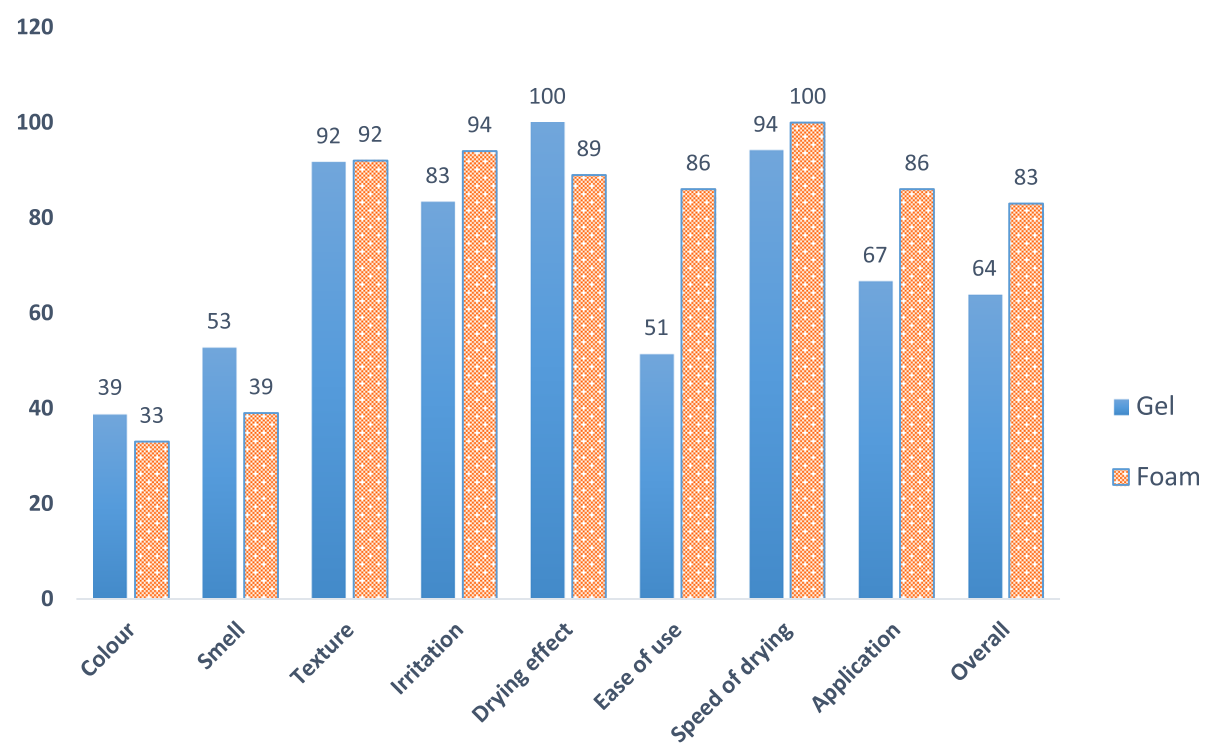

Fig. 2 User acceptability for each of the ABHR products tested*

3); $47 \%$ of subjects were in the mid-normal range at commencement of the study and this increased to $83 \%$ by the end of the study (Fig. 3). There was no evidence of damage to skin integrity caused by either product and in the subjective evaluation of skin assessment; more than $90 \%$ of residents rated their skin integrity as perfect following use of either test product (Table 5).

During the study, we observed that some participants were forgetful and seven (19\%) misplaced their personal bottles of ABHR (Product A). A few subjects suffered from joint stiffness and were unable to rub the product over the entire hands as instructed.

\section{Discussion}

We aimed to determine acceptability and tolerability of two ABHRs for use by elderly residents in long-term care using the WHO protocol Method 2 [16]. We selected one gel and one foam as these formats should be easier to apply, have less drying effect, and be less likely to accidentally spill during use [18]. In the past, doubts

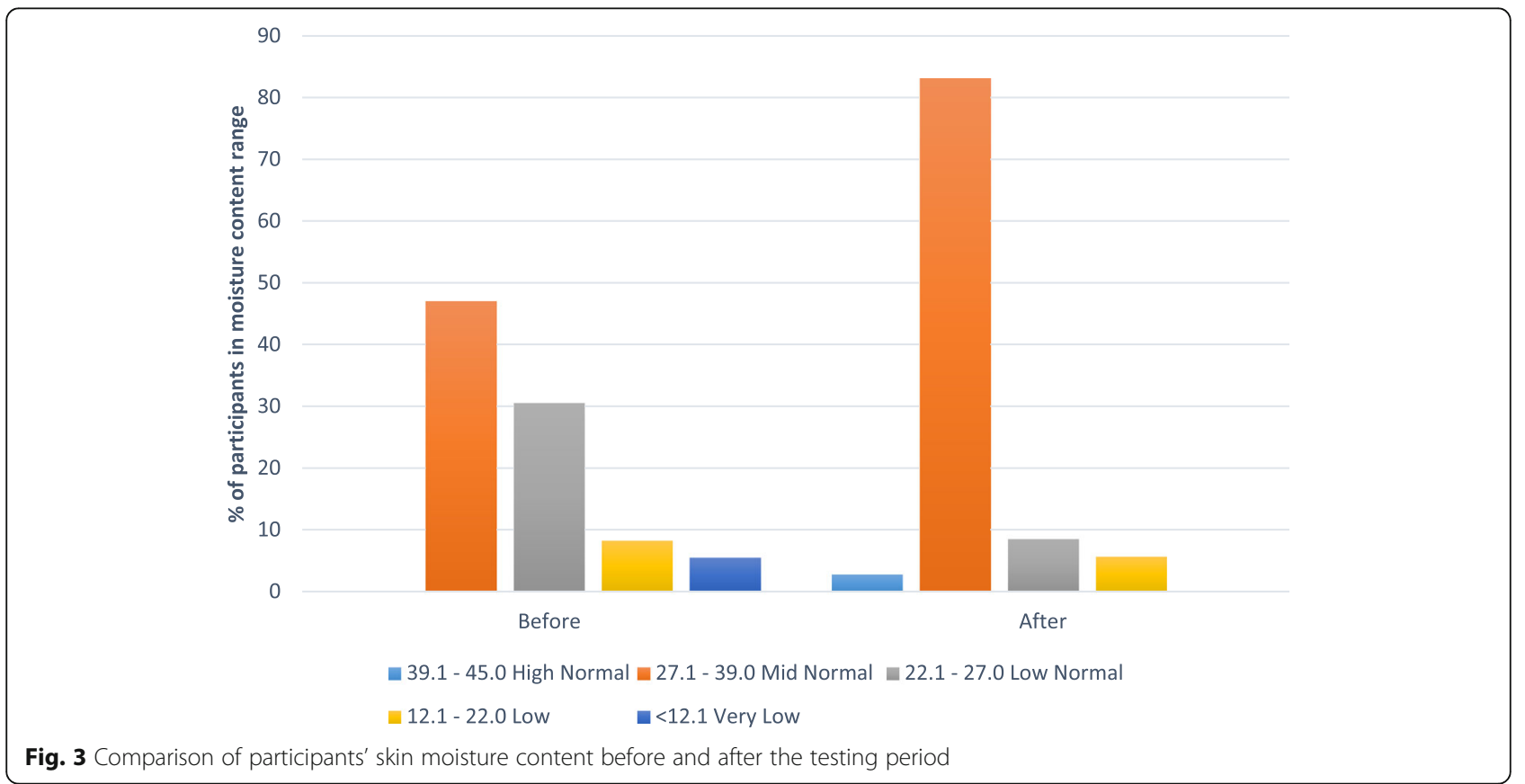


Table 3 Evaluation of frequency of hand hygiene practices

\begin{tabular}{|c|c|c|c|}
\hline & & Product A (Gel) & Product $B \wedge($ Foam) \\
\hline \multirow{6}{*}{$\begin{array}{l}\text { (a) In what percentage of times where hand hygiene is } \\
\text { recommended, did you really clean your hands? }\end{array}$} & Variable & N (\%) & N (\%) \\
\hline & $0-10 \%$ & $11(30.56)$ & $3(8.33)$ \\
\hline & $20-40 \%$ & $12(33.33)$ & $12(33.33)$ \\
\hline & $50-70 \%$ & $6(16.67)$ & $14(38.89)$ \\
\hline & $80-100 \%$ & $7(20.58)$ & $5(13.89)$ \\
\hline & Missing & 0 & $2(5.56)$ \\
\hline \multirow[t]{2}{*}{ (b) Has the present study changed your hand hygiene practice? } & Yes & $18(50 \%)$ & $25(69.44)$ \\
\hline & No & $18(50 \%)$ & $9(25)$ \\
\hline \multirow{8}{*}{$\begin{array}{l}\text { (c) During your last five opportunities for hand hygiene, how } \\
\text { many times did you use handrubbing to clean your hands? }\end{array}$} & 0 & $1(2.78)$ & 0 \\
\hline & 1 & $11(30.56)$ & $10(27.75)$ \\
\hline & 2 & $4(11.11)$ & $13(36.11)$ \\
\hline & 3 & 7 (19.44) & $4(11.11)$ \\
\hline & 4 & $3(8.33)$ & $4(11.11)$ \\
\hline & 5 & $10(27.78)$ & $3(8.33)$ \\
\hline & Missing & 0 & $2(5.56)$ \\
\hline & $<1$ & $1(2.78)$ & 0 \\
\hline \multirow{5}{*}{$\begin{array}{l}\text { (d) On average, how often did you practice hand hygiene } \\
\text { each day (during the test period) }\end{array}$} & $1-5$ & $18(50)$ & $18(50)$ \\
\hline & $6-10$ & $17(47.22)$ & $15(41.67)$ \\
\hline & $11-15$ & 0 & $1(2.75)$ \\
\hline & $>15$ & 0 & 0 \\
\hline & Missing & 0 & $2(5.56)$ \\
\hline
\end{tabular}

$\wedge$ Two subjects were hospitalized during the washout period and were unable to participate in testing of product $B$

had been cast over the efficacy of ABHR gels and foams for hand hygiene [19-21], but more recent studies have concluded that there is no difference in efficacy between new generations of gel or foam formats and liquid (rinse) ABHRs when appropriately applied [22, 23]. To the best of our knowledge, this is the first time the WHO protocol has been used for this demographic.

Our results revealed that the elderly residents preferred both of the test products to the usual one used by the home, which was a liquid rinse formulation containing glycerol as humectant. When comparing test products, there appeared to be a preference for the foam. This is consistent with the findings from some studies investigating preference of ABHR formulation by patients in acute care settings as well as for healthcare workers [11, 24]. Additionally, the foam in our study was provided in a pushdown pump which residents found easier to handle. Product acceptability, including ease of use, is essential in order to ensure user compliance [25]. Subjects in our study found the portable bottles of gel with plastic caps difficult to manipulate. This may explain why this product was rated lower overall than the foam with some elderly misplacing their bottles of gel during the test period.
Product tolerability and skin compatibility are also critical, and studies have demonstrated that a product that is not well tolerated will not be well-accepted [25]. In our study, objective assessment by an independent observer as well as subjective assessment by users demonstrated that both products were well tolerated.

Some of the elderly residents in our study could not perform the hand hygiene steps precisely due to stiffness in their joints or having deformed fingers due to arthritis. Providing individual bottles of ABHR to this group may not lead to improvements in hand hygiene. Even though subjects were deemed cognitively sound and capable of participating in the study, forgetfulness was an issue for a few subjects. Therefore, assistance with hand rubbing would be required for specific residents in order for any intervention to be successful. This could involve the staff of the home placing $500 \mathrm{~mL}$ pump dispensers in communal dining tables immediately before each of the three main mealtimes and prompting residents to perform hand hygiene before dining. ABHR could be dispensed on the hands and gently rubbed over the hands for those requiring assistance, while those capable of performing hand rubbing by themselves could proceed to do so. This strategy could overcome many of 
Table 4 Evaluation of test products and product preference

\begin{tabular}{|c|c|c|c|c|c|}
\hline \multirow[t]{2}{*}{ Question } & \multirow[t]{2}{*}{ Response options } & \multicolumn{2}{|c|}{ Product A } & \multicolumn{2}{|c|}{ Product $B \wedge$} \\
\hline & & $\mathrm{N}$ & $\%$ & $\mathrm{~N}$ & $\%$ \\
\hline \multirow{4}{*}{$\begin{array}{l}\text { Are there differences between the test product } \\
\text { and the product used in this elderly home? }\end{array}$} & Major difference & 4 & 11.11 & 15 & 41.67 \\
\hline & Some & 18 & 50 & 18 & 50 \\
\hline & None & 14 & 38.89 & 1 & 2.78 \\
\hline & Missing & 0 & 0 & 2 & 5.56 \\
\hline \multirow[t]{4}{*}{ Which product do you prefer? } & Test product & 18 & 50 & 25 & 69.44 \\
\hline & Usual product of (RCHE) & 3 & 8.33 & 2 & 5.56 \\
\hline & No difference & 15 & 41.67 & 7 & 19.44 \\
\hline & Missing & 0 & 0 & 2 & 5.56 \\
\hline \multirow{4}{*}{$\begin{array}{l}\text { Do you think that the test product could } \\
\text { improve your hand hygiene compliance? }\end{array}$} & Yes absolutely & 12 & 33.33 & 27 & 75 \\
\hline & No & 5 & 13.89 & 1 & 2.78 \\
\hline & Neutral & 19 & 52.78 & 6 & 16.67 \\
\hline & Missing & 0 & 0 & 2 & 5.56 \\
\hline \multicolumn{6}{|l|}{$\begin{array}{l}\text { Did you have any preference between } \\
\text { the test products used? }\end{array}$} \\
\hline Gel & 0 & 0 & & & \\
\hline Foam & 19 & 52.78 & & & \\
\hline No preference & 15 & 41.67 & & & \\
\hline Missing & 2 & 5.56 & & & \\
\hline
\end{tabular}

\# This question was asked at the end of the testing period $(N=34)$

$\wedge$ Two subjects were hospitalized during the washout period and were unable to participate in testing of product $B$

Table 5 Evaluation of skin condition

\begin{tabular}{|c|c|c|c|c|c|}
\hline \multirow{2}{*}{$\begin{array}{l}\text { D. Evaluation of skin condition } \\
\text { Self-assessment of the skin of your hands } \\
\text { (after use of the test product) }\end{array}$} & & \multicolumn{2}{|c|}{ Product A } & \multicolumn{2}{|c|}{ Product B^ } \\
\hline & & $\mathrm{N}$ & $\%$ & $\mathrm{~N}$ & $\%$ \\
\hline & \multicolumn{5}{|l|}{ Rating } \\
\hline \multirow[t]{3}{*}{ Appearance } & Normal & 35 & 97.22 & 33 & 91.66 \\
\hline & Neutral & 1 & 2.78 & 1 & 2.78 \\
\hline & Missing & 0 & & 2 & 5.56 \\
\hline \multirow[t]{3}{*}{ Intactness } & Normal & 34 & 94.4 & 34 & 94.4 \\
\hline & Neutral & 2 & 5.56 & 0 & 0 \\
\hline & Missing & 0 & & 2 & 5.56 \\
\hline \multirow[t]{3}{*}{ Moisture content } & Normal & 34 & 94.4 & 34 & 94.4 \\
\hline & Neutral & 2 & 5.56 & 0 & 0 \\
\hline & Missing & 0 & 0 & 2 & 5.56 \\
\hline \multirow[t]{3}{*}{ Sensation } & Normal & 34 & 94.4 & 34 & 94.4 \\
\hline & Neutral & 2 & 5.56 & 0 & 0 \\
\hline & Missing & 0 & 0 & 2 & 5.56 \\
\hline \multirow[t]{3}{*}{ Overall integrity of the skin of your hands } & Perfect & 33 & 91.66 & 34 & 94.4 \\
\hline & Neutral & 3 & 8.33 & 0 & 0 \\
\hline & Missing & 0 & 0 & 2 & 5.56 \\
\hline
\end{tabular}

$\wedge$ Two subjects were hospitalized during the washout period and were unable to participate in testing of product B 
the difficulties experienced by providing individual portable bottles to residents and should not put undue burden on the healthcare workers and healthcare assistants of the home. An additional advantage would be the ability to include subjects that are not cognitively sound and who would not normally be able to use ABHR. Interventions for improving hand hygiene in the elderly have been attempted with some success. Schweon et al. (2013) implemented a programme to improve hand hygiene for both staff and residents of a skilled nursing facility in the US and were able to demonstrate reductions in rates of lower respiratory tract infections and surgical site infections over the 22-month period of the study [11]. However, they did not monitor compliance to hand hygiene by residents and did not provide suggestions for long-term sustainability of the intervention [11]. In a separate study, efforts to improve hand hygiene of residents in a LTCF involved a multidisciplinary team to design and implement an intervention that would encourage hand hygiene by residents at mealtimes [26].

In this study, we used a simplified hand rubbing technique based on the three-step method described by Tschudin-Sutter et al. [17] since it is easier to perform and could potentially improve compliance. This method was demonstrated to be as effective as the WHO six-step method for reduction of bacterial counts on the hands of healthy volunteers [17]. Importantly, although named "a three-step method", this simplified technique nevertheless requires the covering of all hand surfaces with $A B H R$, and subsequent rubbing of all hand surfaces, essentially applying the originally described WHO six-step technique, but condensing this to three steps [17].

This study had some limitations. The WHO protocol used [15] was designed for healthcare workers, but it was not possible to use randomization and blinding in our study due to the limitations of the setting. Additionally, since both ABHRs used were commercial preparations, it was not possible to conceal the product type, one being a gel in a portable bottle, the second being a foam pump. Elderly LTCF residents would not be expected to perform hand hygiene as frequently as healthcare workers; thus, we did not insist on use of $30 \mathrm{~mL}$ of product per day. Subjects required assistance in completing the questionnaires. It is possible that they gave the responses they thought would be most appropriate or acceptable to the research nurse. However, there was clearly a difference in responses when determining acceptability of the gel in comparison to the foam ABHR. We did not strictly follow the WHO scale for evaluation of skin condition by an objective assessor, however, the research nurse was able to objectively evaluate skin condition and subjective evaluation ratings were very high. Additionally, many studies have demonstrated that gel and foam ABHRs are gentle on the hands. Finally, participants' acceptability of both products was excellent. It is likely that acceptability could not be achieved if skin tolerability was a problem.

\section{Conclusion}

Overall, the elderly residents in our study were willing and even enthusiastic about using ABHR for hand hygiene. However, supervision and assistance from the staff of the home would be required to prompt them to clean their hands and to assist those whose hands are too stiff to rub the product over the entire hands. Encouraging hand hygiene three times per day during mealtimes should be feasible and sustainable and would not require additional staffing. The majority of participants favoured the foam product and this may be important when attempting to encourage compliance to hand hygiene. Both ABHRs tested fulfilled the WHO criteria for tolerability and acceptability. Given the critical issue of multidrug resistance, the reservoirs of MDROs in residential care settings for the elderly, and the increased staff to resident care often required for elderly with co-morbid conditions, it is essential that efforts to improve hand hygiene in this group be attempted. Improved hand hygiene could reduce the transmission of healthcare associated pathogens and relieve demand on our already dwindling supply of antibiotics.

\section{Supplementary information}

Supplementary information accompanies this paper at https://doi.org/10. 1186/s13756-019-0610-7.

Additional file 1: Tabel S1. (a) Protocol for Evaluation and Comparison of Tolerability and Acceptability of Different Alcohol-based Handrubs: Method 2 (modified) -word document.

Additional file 2: Table S1. (b) Modifications to the WHO checklist for evaluation and comparison of tolerability and acceptability of different alcohol based hand rubs: Method 2, with justification for changes made. -word document. Table S2. Skin Moisture content-interpretation of readings for the Scalar moisture checker probe.

\section{Abbreviations}

ABHR: Alcohol-based hand rub; LTCFs: Long-term care facilities; MDROs: Multi-drug resistant organisms; MRSA: Methicillin resistant Staphylococcus aureus; VRE: Vancomycin resistant enterococci; WHO: World Health Organization

\section{Acknowledgements}

We are grateful to the staff of the LTCF for allowing us access and for assisting in the conduct of this study. We would like to acknowledge the student nurses and elderly ambassadors who provided assistance to the study.

\section{Authors' contributions}

Dr. O'Donoghue was responsible for overall project management. Dr. Lorna Suen provided valuable advice on data analysis and helped with access to the LTCF, Ms. Jacqueline Ho supervised data collection, coordination of student helpers and elderly ambassadors. She was also responsible for objective evaluation of skin tolerability of elderly subjects. Prof Pittet provided advice on study design including use of the $\mathrm{WHO}$ protocol Method 2. All authors read and approved the final manuscript. 


\section{Funding}

This study was funded by a research grant provided by the School of Nursing, The Hong Kong Polytechnic University.

\section{Availability of data and materials}

The datasets used and/or analysed during the current study are available from the corresponding author on reasonable request.

\section{Ethics approval and consent to participate}

Ethical approval for the study was obtained from the Human Subjects Ethics Review Committee of the Hong Kong Polytechnic University (Ethical approval no. HSEARS20151119002) and institutional approval was obtained from the residential care facility. Participation was voluntary. Any resident suffering from dementia, skin dermatitis or other skin conditions, or with a known allergy to alcohol was excluded from the study. An identification code known only to the researcher was assigned to each participant. This code was used on the checklist and the ABHR products A and B. Subjects were provided with a consent form and information sheet in Chinese, clearly explaining the details of the study. All subjects signed a form of consent to participate in the study.

\section{Consent for publication}

Not applicable

\section{Competing interests}

The authors declare that they have no competing interests.

\section{Author details}

${ }^{1}$ Squina International Centre for Infection Control, School of Nursing, The Hong Kong Polytechnic University. Hung Hom, Kowloon, Hong Kong ${ }^{2}$ Infection Control Program and World Health Organization Collaborating Centre on Patient Safety, University of Geneva Hospitals and Faculty of Medicine, Geneva, Switzerland.

Received: 9 July 2019 Accepted: 21 September 2019 Published online: 29 October 2019

\section{References}

1. Dumyati G, Stone ND, Nace DA, Crnich CJ, Jump RL. Challenges and strategies for prevention of multidrug-resistant organism transmission in nursing homes. Curr Infect Dis Rep. 2017;19(4):18. https://doi.org/10.1007/ s11908-017-0576-7.

2. Patel PK, Mantey J, Mody L. Patient hand colonization with MDROs is associated with environmental contamination in post-acute care. Infect Control Hosp Epidemiol. 2017;38(9):1110-3. https://doi.org/10.1017/ice.2017.133.

3. Kahvecioglu D, Ramiah K, McMaughan D, Garfinkel S, McSorley VE, Nguyen QN, Yang M, Pugliese C, Mehr D, Phillips CD. Multidrugresistant organism infections in US nursing homes: a national study of prevalence, onset, and transmission across care settings, October 1 , 2010-December 31, 2011. Infect Control Hosp Epidemiol. 2014;35(Suppl 3):S48-55. https://doi.org/10.1086/677835.

4. Denkinger CM, Grant AD, Denkinger M, Gautam S, D'Agata EM. Increased multi-drug resistance among the elderly on admission to the hospital--a 12year surveillance study. Arch Gerontol Geriatr. 2013;56(1):227-30. https://doi. org/10.1016/j.archger.2012.05.006.

5. Mody L, Washer LL, Kaye KS, Gibson K, Saint S, Reyes K, Cassone M, Mantey J, Cao J, Altamimi S, Perri M, Sax H, Chopra V, Zervos M. Multidrug-resistant organisms in hospitals: What is on patient hands and in their rooms? Clin Infect Dis. 2019 Apr 13. pii: ciz092. doi: https://doi.org/10.1093/cid/ciz092. [Epub ahead of print].

6. Otter JA, Yezli S, French GL. The role played by contaminated surfaces in the transmission of nosocomial pathogens. Infect Control Hosp Epidemiol. 2011;32(7):687-99. https://doi.org/10.1086/660363.

7. Cao J, Min L, Lansing B, Foxman B, Mody L. Multidrug-resistant organisms on patients' hands: a missed opportunity. JAMA Intern Med. 2016 May 1; 176(5):705-6. https://doi.org/10.1001/jamainternmed.2016.0142.

8. Sunkesula V, Kundrapu S, Macinga DR, Donskey CJ. Efficacy of alcohol gel for removal of methicillin-resistant Staphylococcus aureus from hands of colonized patients. Infect Control Hosp Epidemiol. 2015;36(2):229-31. https://doi.org/10.1017/ice.2014.34.
9. Otter JA, Yezli S, Salkeld JA, French GL. Evidence that contaminated surfaces contribute to the transmission of hospital pathogens and an overview of strategies to address contaminated surfaces in hospital settings. Am J Infect Control. 2013;41(5 Suppl):S6-11. https://doi.org/10.1016/j.ajic.2012.12.004.

10. Pineles L, Perencevich EN, Roghmann MC, Gupta K, Cadena J, Baracco G, Pfeiffer CD, Forrest G, Bradley SF, Crnich C, Reisinger HS, Morgan DJ. Frequency of nursing home resident contact with staff, other residents, and the environment outside resident rooms. Infect Control Hosp Epidemiol. 2019|;40(7):815-6. https://doi.org/10.1017/ice.2019.117 Epub 2019 May 20.

11. Schweon SJ, Kirk J. A realistic approach towards hand hygiene for long-term care residents and health care personnel. Am J Infect Control. 2011;39(4): 336-8. https://doi.org/10.1016/j.ajic.2010.09.013.

12. Landers T, Abusalem S, Coty MB, Bingham J. Patient-centered hand hygiene: the next step in infection prevention. Am J Infect Control. 2012;40(4 Suppl 1):S11-7. https://doi.org/10.1016/j.ajic.2012.02.006.

13. Istenes N, Bingham J, Hazelett S, Fleming E, Kirk J. Patients' potential role in the transmission of health care-associated infections: prevalence of contamination with bacterial pathogens and patient attitudes toward hand hygiene. Am J Infect Control. 2013;41(9):793-8. https://doi.org/10.1016/j.ajic.2012.11.012.

14. Haverstick S, Goodrich C, Freeman R, James S, Kullar R, Ahrens M. Patients' hand washing and reducing hospital-acquired infection. Crit Care Nurse. 2017 Jun;37(3):e1-8. https://doi.org/10.4037/ccn2017694.

15. The World Health Organisation (2009). Tools for evaluation and feedback [http://www.who.int/gpsc/5may/tools/evaluation_feedback/en/]: Protocol for Evaluation of tolerability and acceptability of alcohol-based handrub in use or planned to be introduced: Method 2. [http://www.who.int/entity/ gpsc/5may/Protocol_for_Evaluation_of_Handrub_Meth2.doc?ua=1] Accessed June 302019.

16. Hand Hygiene: Why, How \& When? The World Health Organisation 2009. https://www.who.int/gpsc/5may/Hand_Hygiene_Why_How_and_When_ Brochure.pdf Accessed June 302019

17. Tschudin-Sutter S, Rotter ML, Frei R, Nogarth D, Häusermann P, Stranden A, Pittet D, Widmer AF. Simplifying the WHO 'how to hand rub' technique: three steps are as effective as six-results from an experimental randomized crossover trial. Clin Microbiol Infect. 2017;23(6):409.e1-409.e4. doi: https:// doi.org/10.1016/j.cmi.2016.12.030.

18. Greenaway RE, Ormandy K, Fellows C, Hollowood T. Impact of hand sanitizer format (gel/foam/liquid) and dose amount on its sensory properties and acceptability for improving hand hygiene compliance. J Hosp Infect. 2018;100(2):195-201. https://doi.org/10.1016/j.jhin.2018.07.011.

19. Kramer A, Rudolph P, Kampf G, Pittet D. Limited efficacy of alcohol-based hand gels. Lancet. 2002;359:1489-90.

20. Kampf G, Marschall S, Eggerstedt S, Ostermeyer C. Efficacy of ethanol-based hand foams using clinically relevant amounts: a cross-over controlled study among healthy volunteers. BMC Infect Dis. 2010;10:78.

21. Dharan S, Hugonnet S, Sax H, Pittet D. Comparison of waterless hand antisepsis agents at short application times: raising the flag of concern. Infect Control Hosp Epidemiol. 2003:24:160e4

22. Larson EL, Cohen B, Baxter KA. Analysis of alcohol-based hand sanitizer delivery systems: efficacy of foam, gel, and wipes against influenza a (H1N1) virus on hands. Am J Infect Control. 2012;40(9):806-9. https://doi.org/10. 1016/j.ajic.2011.10.016.

23. Wilkinson MAC, Ormandy K, Bradley CR, Hines J. Comparison of the efficacy and drying times of liquid, gel and foam formats of alcohol-based hand rubs. J Hosp Infect. 2018;98(4):359-64. https://doi.org/10.1016/j.jhin.2017.09.024.

24. Tanner J, Mistry N. Hand hygiene: product preference and compliance. Nurs Times. 2011:107(6):16-9.

25. Pittet D, Allegranzi B, Sax H, Chraiti MN, Griffiths W. Richet H; World Health Organization global patient safety challenge alcohol-based Handrub task force. Double-blind, randomized, crossover trial of 3 hand rub formulations: fast-track evaluation of tolerability and acceptability. Infect Control Hosp Epidemiol. 2007;28(12):1344-51.

26. O'Donnell M, Harris T, Horn T, Midamba B, Primes V, Sullivan N, Shuler R, Zabarsky TF, Deshpande A, Sunkesula VC, Kundrapu S, Donskey CJ. Sustained increase in resident meal time hand hygiene through an interdisciplinary intervention engaging long-term care facility residents and staff. Am J Infect Control. 2015;43(2):162-4. https://doi.org/10.1016/j.ajic.2014.10.018.

\section{Publisher's Note}

Springer Nature remains neutral with regard to jurisdictional claims in published maps and institutional affiliations. 